\title{
ARQUEOLOGIA FUNERÀRIA AL NORD-EST PENINSULAR (SEGLES VI-XII) \\ Núria Molist y Gisela Ripoll (eds.)
}

Barcelona, Monografies d'Olèrdola 3.I y 3.2,

Museu d'Arqueologia de Catalunya-Olèrdola, 2012, 494 págs.

Treinta años después de la publicación del anexo de Acta historica et archaeologica mediaevalia dedicado a las Necròpolis i sepultures medievals de Catalunya, esta obra coral aspira a convertirse en sucesora de la ya larga tradición investigadora catalana sobre la arqueología funeraria de época medieval. No cabe duda de que era necesario tomar el relevo y continuar la labor, sobre todo en una cuestión clave en la que se ha avanzado bastante en las últimas décadas y a la que estaban consagradas las jornadas de las que Arqueologia funerària al nord-est peninsular levanta acta: los problemas de cronología. Pero no sólo de eso trata esta obra que, seguramente, no tardará en convertirse también en referencia imprescindible para los investigadores sobre el tema. Sus dos tomos y casi quinientas páginas recogen, con una cuidada edición, tres tipos de trabajos: artículos de carácter general, síntesis sobre comarcas, ciudades o grandes yacimientos y estudios más concretos sobre yacimientos o conjuntos de yacimientos, en muchos de los cuales se presentan resultados inéditos.

Los trabajos de carácter general se concentran al principio de la obra, sirviendo de introducción y encuadre al tema que trata. Las editoras de la obra (N. Molist y G. Ripoll) realizan una introducción en la que se detienen en cuestiones conceptuales, en la definición de categorías de análisis para el estudio de la arqueología funeraria medieval, en las metodologías utilizadas hasta el presente $y$ en los enfoques necesarios para las investigaciones futuras. J. I. Padilla y K. Álvaro le dedican un trabajo a la figura de Alberto del Castillo, pionero en la investigación sobre el cementerio altomedieval en Cataluña y Castilla, repasando su aportación al establecimiento de la cronología de las tumbas excavadas en la roca; y otro en el que, completando la introducción de las editoras, plantean un estado actual de conocimiento sobre los espacios funerarios altomedievales de las tres religiones protagonistas en la península Ibérica: cristianos, musulmanes y judíos. Le prestan especial atención al cementerio cristiano, algo inexcusable en tanto que es el protagonista de la obra, sobre todo desde un punto de vista diacrónico, llamando la atención sobre los avances en el estudio de su evolución que se han producido en los últimos años. La colaboración de J. Bolós ofrece un nexo de unión directo con Necròpolis i sepultures medievals de Catalunya, ya que el autor toma como punto de partida su trabajo sobre las tumbas excavadas en la roca de 1982 para reflexionar sobre la necesidad de estudiar el fenómeno desde el punto de vista del paisaje histórico. Las páginas de visión general se completan con dos aportaciones específicamente metodológicas, una dedicada al papel de la antropología y la paleopatología en el estudio de la arqueología funeraria (B. Agustí, D. Codina, A. Díaz y J. A. Ginestà), abogando por la colaboración interdisciplinar, y otra que trata, como no podía ser de otro modo en una obra que nace ligada al debate cronológico, de la técnica de datación radiocarbónica y sus posibilidades de aplicación al periodo en estudio (J. Mestres).

Entre los trabajos de síntesis destacaremos, el primer lugar, el único que no está dedicado específicamente a la problemática de los cementerios cristianos altomedievales. J. Casanovas y X. Maese abordan la cuestión de la pervivencia de las tumbas antropomorfas más allá de la Alta Edad Media en las necrópolis judías catalanas, donde se siguen utilizando hasta el siglo XV.

Las otras colaboraciones de síntesis reflejan la amplia trayectoria en la investigación sobre el cementerio cristiano que se viene desarrollando en Cataluña en la últimas décadas. J. Menchón ofrece un estado de la cuestión sobre las comarcas septentrionales de la provincia de Tarragona, en la que recoge un detallado inventario sobre los cementerios de ámbito urbano, los de carácter rural y las necrópolis aisladas. Se presentan también los resultados de diversas excavaciones realizadas en lesso ( J. Pera y ). Guitart) que están permitiendo conocer mejor el tránsito de Antigüedad a la Edad Media. Otro interesante compendio regional que propone una interpretación evolutiva es el que se dedica a las comarcas de Girona entre los siglos $V$ y XII (J. Llinàs, B. Agustí, A. Farjas, J. Frigola y C. Montalbán). EI modelo de evolución tipológica de las tumbas, apoyado en dataciones de ${ }^{14} \mathrm{C}$, muestra un cambio significativo desde la complejidad y variabilidad bajoimperial, que conduce a una simplificación en la Antigüedad Tardía. Por su parte, las necrópolis tardoantiguas y altomedievales de Empuries (J. Tremoleda, P. Castanyer y M. Santos) se presentan como un ejemplo de evolución compleja, en un periodo de tiempo largo, ligadas a los cambios en los centros de culto a las que se asocia la mayoría. A. López ofrece un estado de la cuestión sobre el llamado "suburbio funerario" de Barcino, en el que cementerios o grupos de sepulturas de diferente entidad ayudan a trazar el desarrollo de los espacios funerarios de la ciudad.

A medio camino entre la síntesis y el estudio de yacimientos encontramos uno de los trabajos que, según nuestro criterio, mejor define la filosofía de la obra. Es el que dedican J. Roig y J. M. Coll a resumir quince años de investigaciones en los territoria de Barcino y Egara entre los siglos $\vee$ y $X I I$, abordando principamente la problemática cronológica. A partir de las excavaciones realizadas en varios yacimientos, plantean una propuesta de alcance comarcal para el periodo estudiado con seis modelos de 
cementerio y una tipo-cronología en el que se definen trece tipos de sepulturas, convenientemente respaldada en dataciones de ${ }^{14} \mathrm{C}$.

Los trabajos que recogen estudios de yacimientos o conjuntos de yacimientos son quizá la parte más heterogénea de la obra pero, sin duda, la que más novedades aporta. Se trata, en la mayor parte de los casos, de actuaciones ligadas a lo que se conoce como "arqueología de gestión", que en muchas ocasiones es más bien "de salvamento", como lo son también buena parte de las que han proporcionado datos para las síntesis comarcales - locales que hemos mencionado más arriba.

Una quincena de colaboraciones dedicadas tanto a yacimientos conocidos como a los recientemente descubiertos en Cataluña y Andorra, que trazan un panorama complejo y rico para el tema que aborda la obra. De los enterramientos dispersos localizados en los niveles tardoantiguos de llerda (M. Morán, I. Gil, X. Payá y A. Loriente), hasta enclaves clásicos como la Esquerda (I. Ollich) o Santa Margarida (M. Farreny, A. Mauri y R. Navarro) en los que se retoman o continúan excavaciones iniciadas en la década de 1980, pasando por las dos únicas necrópolis abiertamente consideradas "de época visigoda" en Cataluña: Pla de l'Horta y Goges (B. Agustí y J. Llinàs), el abanico de estudios es amplio, con destacadas incorporaciones que aportan datos sobre los periodos menos definidos como son la época tardorromana y la tardoantigua. Un buen exponente es la necrópolis de Morulls (A. Camats), con una cronología estimada entre los siglos IV y VII, de cuya excavación se presentan en esta obra los primeros resultados. Y no es el único caso en el que se aprovechan estas páginas para ofrecer un avance de actuaciones en curso o recientemente concluidas que aún no habían sido publicadas. Así sucede con las necrópolis andorranas de Hort de l'Eglise, Camp del Perot y Camp Vermell (A. Fortó, $X$. Maese y A. Vidal), que permiten trazar una propuesta tipo-cronológica apoyada en dataciones radiocarbónicas en la que se refleja la complejidad y la variabilidad de las tumbas, y la coexistencia de los diferentes tipos. C. Subiranas, por su parte, da a conocer los resultados de la excavación efectuada en Santa Maria la Rodona de Vic, donde se ha documentado un cementerio con diferentes niveles de uso entre el siglo XI y el XIX. También se presentan en estas páginas la necrópolis de San Esteve de Canapost (J. Frigola y D. Punseti), que ha proporcionado más de trescientas sepulturas entre los siglos IX y $X V$ repartidas en tres fases, definidas mediante criterios estratigráficos y dataciones de ${ }^{14} \mathrm{C}$, y la necrópolis de Sant Quirze i Santa Julita (M. López-Prat y E. García-Giuxé), utilizada entre los siglos VI y XIII. Igualmente necesaria era, sin duda, la publicación de la necrópolis de Tossal de les Forques (J. R. González, J. Medina, M. P. Vázquez y J. I. Rodríguez), excavada en la década de 1980 y que permanecía inédita.
El cuadro se completa con otros yacimientos ya publicados, pero que aportan interesantes datos a la discusión cronológica, como Sant Martí de les Tombetes (N. Nolasco), con sus tumbas excavadas en la roca para las que se buscan conexiones norpirenaicas; Roc d'Enclar (J. M. Bosch), abordando en esta ocasión el yacimiento desde un enfoque sistémico que permita explicar la relaciones entre los lugares de hábitat, los cementerios y las iglesias en los siglos VI-IX; las necrópolis de la comarca del Berguedà y del Bages, sobre las que A. López Mullor ofrece la propuesta cronológica más apegada a la tradición historiográfica anterior de cuantas se presentan en la obra; y la necrópolis del complejo episcopal de Ègara (M. G. García, A. Moro y F. Tuset), cuya evolución se relaciona con la de la propia arquitectura y los cambios de función de los espacios.

Cierra la obra un yacimiento emblemático como es Sant Miquel d'Olèrdola (N. Molist y J. M. Bosch), epónimo de las tumbas "olerdolanas", apelativo ya caído en desuso, en el que los nuevos hallazgos y las dataciones radiocarbónicas demuestran que aún queda mucho que aprender sobre los cementerios altomedievales.

Un apunte destacable sobre la cuestión cronológica: en las páginas de esta obra se recogen más de cincuenta dataciones radiocarbónicas de diecisiete yacimientos diferentes de Cataluña y Andorra que contribuyen, en gran medida, a acotar el lapso temporal de utilización de muchos espacios cementeriales. En relación con este asunto, muchos trabajos llegan a la conclusión de que los sencillos esquemas tradicionales que planteaban una sucesión diacrónica de tipos de tumbas esconden una realidad mucho más compleja y rica en matices, en la que esos tipos coexisten, se solapan y se alternan en cementerios cuyas secuencias se deben entender partiendo de un análisis estratigráfico preciso, apoyado en el recurso sistemático de las dataciones absolutas.

En conjunto, la obra aporta un compendio de trabajos que permiten comprender cómo se ha desarrollado la investigación sobre la arqueología funeraria de época tardoantigua y medieval en el nordeste peninsular en los últimos 30 años. Es un estado de la cuestión muy completo en el que se refleja una vocación de continuidad y un compromiso con un ámbito de estudio en el que los investigadores catalanes -en sentido amplio- siempre han tenido un papel protagonista. Es interesante comprobar cómo esta tradición historiográfica se va transformando sin demasiados traumas, gracias a la incorporación de un incesante flujo de nuevos datos, y se adapta a las tendencias más actuales.

Enrique Gutiérrez Cuenca Proyecto Mauranus 